\title{
Predileção de substrato por espécies hematófagas de simuliidae (diptera) da região sudeste do Brasil para controle vetorial
}

A família Simuliidae ocorrem regiões de ambientes lóticos, como rios e riachos, ambientes muito abundantes no Brasil, principalmente na região Sudeste do país. Assim como outros dípteros, eles apresentam a necessidade de realizar o repasto sanguíneo, abrindo, assim, uma via vetorial para patógenos e diferentes enfermidades. Os principais patógenos atrelados à picada das espécies de simulídeos são filárias, do gênero Mansonella e da espécie Onchocerca Volvulus. Esses parasitas são perigosos, pois causam diversas comorbidades. Além disso, os simulídeos apresentam a capacidade de gerar agravos imunológicos e alérgicos em animais e humanos. Por se tratar de um vetor causador de doenças em humanos e animais, existe uma necessidade de controle dos simulídeos. Dentre as medidas tomadas para o controle das espécies dessa família, temos métodos químicos, físicos e biológicos. 0 objetivo deste trabalho foi realizar uma revisão bibliográfica para verificar quais espécies hematófagas são encontradas na região Sudeste do Brasil, bem como mostrar em quais substratos esses organismos são mais observados, afim de mostrar a profilaxia adequada para o controle desses organismos. Como método para tais feitos, foram analisados artigos, dissertações e teses de levantamento faunístico em estados da região Sudeste, além de analisar minunciosamente as características bioecológicas das espécies encontradas... Fo obtido, como resultado, a ocorrência de 12 espécies hematófagas evidenciadas na região Sudeste, bem como a preferência destas, em sua maioria, por substratos rochosos ou de folhiço, mostrando que profilaxias como a raspagem ou retirada desses substratos dos corpos hídricos ajuda no controle populacional desses organismos e diminui os impactos ao meio ambiente.

\section{Predilection of substrate by hematophagous species of simuliidae (diptera) from southeastern Brazil for vector control}

The Simuliidae family occurs in regions of lotic environments, such as rivers and streams, very abundant environments in Brazil, mainly in the Southeast region of the country. Like other dipterans, they have the need to perform a blood meal, thus opening a pathway for pathogens and different diseases. The main pathogens linked to the bite of the species of simulids are filarial, of the genus Mansonella and of the species Onchocerca Volvulus. These parasites are dangerous because they cause several comorbidities. In addition, simulids have the ability to generate immunological and allergic diseases in animals and humans. Because it is a vector that causes disease in humans and animals, there is a need to control the simulids. Among the measures taken to control the species of this family, we have chemical, physical and biological methods. The objective of this work was to carry out a bibliographic review to verify which hematophagous species are found in the Southeast region of Brazil, as well as to show which substrates these organisms are most observed in order to show the adequate prophylaxis for the contro of these organisms. As a method for such achievements, articles, dissertations and theses of fauna survey were analyzed in states of the Southeast region, in addition to thoroughly analyzing the bioecological characteristics of the species found... As a result, the occurrence of 12 hematophagous species evidenced in the region was obtained. Southeast, as well as their preference, mostly for rocky or leafy substrates, showing that prophylaxis such as scraping or removing these substrates from water bodies helps in the population control of these organisms and reduces impacts on the environment.

Keywords: Anthropophilic; Vector; Insects; Microenvironment.

\section{Topic: Fundamentos de Biodiversidade}

Reviewed anonymously in the process of blind peer.
Received: 05/12/2020

Approved: 20/02/2021

Ruann Guimarães dos Santos (iD

Faculdade Cenecista de Rio das Ostras, Brasil

http://lattes.cnpq.br/7726682036401916

http://orcid.org/0000-0002-2805-4401

ruannguimaraes98@gmail.com

Willian Rodrigues da Costa Marinho (iD

Instituto de Biodiversidade e Sustentabilidade, Brasil

http://lattes.cnpq.br/8236809033603146

http://orcid.org/0000-0002-2076-9648

will.bio2016@gmail.com

d

DOI: 10.6008/CBPC2318-2881.2021.001.0001
Referencing this:

SANTOS, R. G.; MARINHO, W. R. C.. Predileção de substrato por espécies hematófagas de simuliidae (diptera) da região sudeste do Brasil para controle vetorial. Nature and Conservation, v.14, n.1, p.111, 2021. DOI: http://doi.org/10.6008/CBPC2318-2881.2021.001.0001 


\section{INTRODUÇÃO}

Os insetos hematófagos são animais presentes de maneira relevante na área da medicina e veterinária, sendo estudados em diversos setores por conta do seu risco à saúde humana e animal, já que necessitam, em sua dieta, tanto de maneira restrita quanto de forma suplementar para as fêmeas, material sanguíneo de animais vertebrados para completar o seu ciclo gonotrófico. Dessa forma, abre-se uma via de contágio para possíveis patógenos, tornando-os, assim, vetores eficazes (FARIAS, 2013; FONTES et al., 2005; TAUIL, 2002).

Dentre os insetos vetores existe uma ordem que se destaca por conta de diferentes exemplares de suas espécies por se distribuírem em ambientes urbanos, adaptando-se bem ao convívio com seres humanos. Esses animais apresentam ampla distribuição pelo mundo e são conhecidos, na literatura, como dípteros. Os Dípteros são uma ordem que corresponde a moscas e mosquitos, tendo como integrantes diversos insetos com relevância vetorial, por conta de seus hábitos hematófagos ou parasitas sendo eles: os mosquitos do gênero Aedes e Culex, além de algumas moscas; dentre elas, algumas parasitoides, como a Mosca do Berne (Dermatobiahominis), flebotomíneos, vulgarmente conhecidas como moscas da areia ou mosquitos palha, e uma família muito importante em estudos de ambientes lóticos, conhecida por Simuliidae (FARIAS, 2013; FONTES et al., 2005; TAUIL, 2002).

Os simulídeos são insetos pertencentes à família Simuliidae, conhecidos popularmente como "borrachudos", "piuns" ou "casquinhos de couro". Há espécies encontradas no mundo todo, exceto nos pólos. No entanto, esses organismos apresentam preferência por climas mais quentes e úmidos, o que os torna uma espécie adaptada para climas tropicais e subtropicais. O seu ciclo de vida tem duas fases, uma aquática, em que se desenvolvem os estágios imaturos de ovo, larva e pupa e uma fase terrestre caracterizada pelo desenvolvimento do mosquito adulto (COSCARÓN, 1981; AMARAL-CALVÃO et al., 2003).

O ciclo de vida desses insetos se inicia quando o ovo é posto pela fêmea em um substrato como: pedras, galhos, folhas, plantas aquáticas e até materiais diversos descartados indevidamente, como lixo, e que permanecem submersos, próximos à superfície da água. Os ovos são postos em massas e recobertas por um muco solidificado que os protegem da correnteza e que, após um período de incubação, que pode variar de 4 a 6 dias, de acordo com a espécie e as características ambientais, eclodem em um estágio de larva (PETRY et al., 2006; RIBEIRO, 2018).

Após a eclosão, as larvas caminham pelo substrato com movimentos mede-palmos, utilizando um par de ventosas localizadas na parte final do abdômen e a outra em um apêndice conhecido como pró-leg. Juntamente com uma seda, produzida por glândulas no abdômen do inseto, permitem a aderência ao substrato em meio à correnteza. Utilizando-se de dois apêndices especializados, chamados de leques cefálicos, localizados na região frontal superior da cabeça, as larvas captam partículas que são trazidas pela corrente e que servem de nutrientes para sua alimentação, tais características de filtradores das larvas de simulídeo apresentam uma importância ecológica, retirando os nutrientes dispersos na água e os reintegrando a teia alimentar. As larvas, então, passam por diversos estágios de ecdise, podendo variar de 
sete a nove instares de acordo com a espécie. Após esses estágios, elas se envolvem em um casulo de seda, firmando-se próximo à superfície da água e iniciando a sua metamorfose para o estágio de amadurecimento, denominada pupa (PETRY, 2005; RIBEIRO, 2018).

No estágio de pupa dentro do casulo, o simulídeo não se alimenta e nem se locomove, apenas utiliza um par de filamentos branquiais para realizar trocas gasosas durante sua metamorfose. Após o período de desenvolvimento do casulo, este se rompe e o organismo flutua até a superfície da água dentro de uma bolha de água, quando emerge em um mosquito adulto (CROSSKEY, 1990; PETRY, 2005).

Ao ganhar asas, os adultos voam polinizando flores e se alimentando de néctar de planta que servirá como alimento e energia para realização de funções biológicas e ecossistêmicas. No caso das fêmeas, o néctar de flores não é o suficiente para o desenvolvimento e maturação dos ovos, tendo esta que realizar um repasto sanguíneo em vertebrados como: mamíferos, incluindo humanos e aves (CROSSKEY, 1990; PETRY, 2005).

Durante o repasto sanguíneo, os simulídeos abrem uma via vetorial para diferentes patógenos. Em regiões da África e América do Sul, são transmissores de parasitas sanguíneos como: Onchocerca volvulus, causador da Oncorcercose, doença também conhecida como cegueira dos rios e a Mansonella, parasita causadora da Mansolenose, ambas nematoides parasitas pertencentes ao grupo das filárias e capazes de gerar problemas severos de saúde pública. Essas doenças parasitárias foram erradicadas das regiões Sul e Sudeste do Brasil por conta de atividades de combate ao vetor, tendo, hoje, apenas casos na região amazônica. Contudo, animais hematófagos não necessitam de um patógeno para ser um risco para a população humana de um local (SHELLEY et al., 1976; CHAGAS, 2011).

Os hábitos hematófagos e antropofílicos geram diversos problemas de saúde, não apenas carreando vírus e parasitas, mas também gerando problemas alérgicos severos. Em muitos casos, a exposição prolongada à saliva de certas espécies de simulídeos ocasiona uma doença autoimune nomeada de Fogo Selvagem, uma variante de doenças conhecidas como Pênfigos, tendo como principais sintomas: bolhas, inchaço e coceira intensa na pele. Essa doença, muitas vezes, não tem cura, possuindo apenas tratamento. Esse é um problema não apenas de caráter médico, mas também veterinário, visto que animais podem ser alvos da picada de simulídeos (AMARAL-CALVÃO et al., 2003; PETRY, 2005; RIBEIRO, 2018).

Os simulídeos podem gerar problemas na agropecuária e, por consequência, na economia local. Sua picada pode ser capaz de debilitar e até matar animais de pequeno, médio e grande porte, incluindo animais de produção do agronegócio como: galinhas, porcos e também gado, ou animais domésticos, como cães e gatos (DELLOME FILHO, 1991; CHAGAS, 2011).

Contudo, mesmo sendo animais prejudiciais aos seres humanos, os integrantes da família Simuliidae desempenham um papel muito importante no equilíbrio ecológico de ambientes lóticos sendo os mesmos organismos filtradores da base da teia alimentar, tendo sua população aumentando ou diminuindo de acordo com variáveis ambientais como: concentração de nutrientes da água, salinidade e nível de oxigênio, podendo esses fatores, muitas vezes, apresentar influência pela presença humana em um local (VIVIANI et al., 2012).

O despejo de dejetos nos corpos hídricos, juntamente com o descarte indevido de lixo não 
biodegradável, pode influenciar a população de simulídeos, já que dejetos orgânicos, como fezes e ração de animais, influenciam na quantidade de nutrientes e sais minerais disponíveis dentro do ambiente, como a concentração de fósforo e nitrogênio, que por sua vez aumentam a concentração de micro-organismos e algas, ampliando assim os alimentos disponíveis para organismos filtradores. Se tratando de material não biodegradável, como plástico, vidro e metal, a concentração desses materiais em um fluxo de água amplia a quantidade de substrato no qual os simulídeos podem aderir e, por consequência, aumentam sua população em um corpo hídrico. Esse aumento populacional leva, muitas vezes, à adesão de profilaxias para diminuição desses insetos em regiões populacionais (ANDRADE et al., 2004).

Para diminuir a população da família Simuliidae em uma determinada área, certos procedimentos são tomados tanto em relação ao rio, quanto aos estágios imaturos do simulídeo. As principais profilaxias a serem adotadas são: profilaxias de via mecânica ou química e profilaxias biológicas. A via de tratamento utilizando materiais químicos e biológicos consiste basicamente em inserir um produto químico ou de origem biológica em meio à correnteza para eliminar os estágios imaturos, porém, por se tratar de um método com base química ou bacteriana, podem ocorrer danos ao ambiente, impactando a fauna de macroinvertebrados e vertebrados aquáticos e a qualidade da água (ALVES, 2019).

Em relação ao método mecânico, é feito a retirada de materiais do fluxo de água, como folhagem, galhos e materiais não degradáveis, o que diminui a adesão das lavas a esses substratos. É realizada também a raspagem de rochas em correntezas, já que determinadas espécies têm preferência por tipos diferentes de substratos e diferentes vasões de água. Assim, há a necessidade de estudos envolvendo o microambiente em que cada espécie se desenvolve, principalmente aqueles considerados vetores, podendo assim observar quais são os substratos de preferência de cada vetor, e combatendo assim de maneira assertiva (ANDRADE et al., 2004).

Ao entender os fatores de ocorrência e distribuição, ecológicos e comportamentais da família Simullidae, pode-se alterar características que incentivam e determinam o seu desenvolvimento como, por exemplo, a retirada de um substrato, fator este que se mostra essencial para o ciclo de simulídeos. Tal desejo de controle está associado à capacidade vetorial e enfermidades atreladas às picadas dos adultos de determinadas espécies (BUFFOLO et al., 2016).

O presente trabalho tem como objetivo, através desta revisão, compreender a quantidade de espécies hematófagas presentes na região Sudeste e sua predileção de substratos. E com esse levantamento podemos inferir a melhor estratégia para o controle populacional desses insetos.

\section{MATERIAIS E MÉTODOS}

Foram utilizados como base de pesquisa para o presente trabalho ao todo 44 materiais bibliográficos entre artigos, dissertações, teses e manuais retirados de veículos de divulgação digital, como Scielo, Pubmed e Google Acadêmico para a obtenção de conteúdo referente ao tema a partir do ano de 1980 até 2018, esse período de tempo foi selecionado por relação aos resultados defasados e muito pouco evidentes antes de 1980, sendo selecionados apenas documentos relacionados a levantamento faunísticos, específicos para os 
estados da região sudeste, juntamente com artigos que tratem da ecologia e preferência por substratos dessas espécies encontradas.

Os descritores utilizados para a pesquisa foram: Simulium, hematophagous, substrate. Em um segundo momento, foram incluídas as palavras: microenvironments e Southeast region of Brazil, além do nome específico de cada espécie de simulídeo hematófago encontrado na região Sudeste.

Para a delimitação das espécies encontradas na região Sudeste, foram utilizados, especialmente, inventários taxonômicos específicos do Sudeste brasileiro, como publicado por Gil-Azevedo et al. (2005; 2014), Pereira (2011), Pepinelli (2003) e Bertazo et al. (2010). A predileção de microambientes e hábitos hematófagos foi encontrada através de artigos científicos relacionados à área de Ecologia e Saúde.

\section{RESULTADOS E DISCUSSÃO}

De acordo com o levantamento bibliográfico realizado para região Sudeste do Brasil, como mostra a tabela 1, ao todo foram catalogados cinquenta e uma espécies de Simulídeos. Contudo, nem todas as espécies são consideradas hematófagas. A tabela 1 mostra que apenas doze espécies são assim denominadas pela literatura, apresentando evidências de sua relação hematófaga, médica ou veterinária. Todas as outras espécies encontradas são consideradas, em sua maioria e até o momento, inofensivas, tanto para humanos quanto para outros animais não humanos (GINARTE et al., 2003; GIL-AZEVEDO et al., 2009; PEPINELLI, 2003; BERTAZO et al., 2013)

Tabela 1: Distribuição de espécies de simulídeos encontradas por estados da região Sudeste, bem como total e descrição de espécies consideradas hematófagas (espécies hematófagas em vermelho e outras em azul).

\begin{tabular}{|c|c|c|c|c|}
\hline Estados & São Paulo & Espírito Santo & Minas Gerais & Rio de Janeiro \\
\hline \multirow[t]{2}{*}{ Espécies } & $\begin{array}{l}\text { S.acarayense, } \\
\text { S.anamariae } \\
\text { S.aneportoi, } \\
\text { S.auristriatum, } \\
\text { S.bifenestrarum, } \\
\text { S.brachicladum } \\
\text { S.brevifurcatum, } \\
\text { S.clavibranchium, } \\
\text { S.cuasiexiguum } \\
\text { S.distinctum } \\
\text { S.diversibranchium, } \\
\text { S.hirticosta } \\
\text { S.incrustatum } \\
\text { S.mariavulcanoae, } \\
\text { S.metalicum } \\
\text { S.nigrimanum } \\
\text { S.obesum } \\
\text { S.oyapockense } \\
\text { S.pernigrum } \\
\text { S.perflavums,pertinax } \\
\text { S.rappae } \\
\text { S.riograndense, } \\
\text { S.rubrithorax } \\
\text { S.stellatum } \\
\text { S.subclavibranchium, } \\
\text { S.trvassosi }\end{array}$ & $\begin{array}{l}\text { S.anamariae } \\
\text { S.angrense } \\
\text { S.botulibrachium } \\
\text { S.brachycladum } \\
\text { S.clavibranchium, } \\
\text { S.dinnelii, } \\
\text { S.distinctum, } \\
\text { S.exiguum, } \\
\text { S.guianense, } \\
\text { S.hirticosta, } \\
\text { S.hirtipupa, } \\
\text { S.inaequale, } \\
\text { S.incrustatum, } \\
\text { S.jujuyense, } \\
\text { S.laneportoi, } \\
\text { S.lutzianum, } \\
\text { S.minusculum, } \\
\text { S.nigrimanum, } \\
\text { S.perflavum, } \\
\text { S.pertinax, } \\
\text { S.petropolinense, } \\
\text { S.rappae, } \\
\text { S.rubrithorax, } \\
\text { S.scutistriatum, } \\
\text { S.spinibranchium, } \\
\text { S.subnigrum, } \\
\text { S.trravassosi }\end{array}$ & $\begin{array}{l}\text { S.auripellitum, } \\
\text { S.auristriatum, } \\
\text { S.botulibranchium, } \\
\text { S.brachycladum, } \\
\text { S.clavibranchium, } \\
\text { S.distinctum, } \\
\text { S.duodenicornium, } \\
\text { S.hirtipupa, } \\
\text { S.incrustatum, } \\
\text { S.laneportoi, } \\
\text { S.mariavulcanoae, } \\
\text { S.obesum, } \\
\text { S.papaveroi, } \\
\text { S.perflavum, } \\
\text { S.pernigrum, } \\
\text { S.pertinax, } \\
\text { S.rappae } \\
\text { S.rubrithorax, } \\
\text { S.serranum, } \\
\text { S.subclavibranchium, } \\
\text { S.subpallidum, } \\
\text { S.subnigrum, } \\
\text { S.scutstriatum, } \\
\text { S.stellatum, }\end{array}$ & $\begin{array}{l}\text { S.pertinax, } \\
\text { S.flavopubescens, } \\
\text { S.hirticosta, } \\
\text { S.pernigrum, } \\
\text { S.distinctum, } \\
\text { S.laneportoi, } \\
\text { S.subpallidum, } \\
\text { S.clavibranchium, } \\
\text { S.inaequali, } \\
\text { S.petropolinense, } \\
\text { S.rappae, } \\
\text { S.souzalopesi, } \\
\text { S.subclavibranchium, } \\
\text { S.anamariae, } \\
\text { S.angrense, } \\
\text { S.incrustatum, } \\
\text { S.enpascae, } \\
\text { S.riograndense, } \\
\text { S.spinibranchium, } \\
\text { S.brachycladum, } \\
\text { S.rubrithorax, } \\
\text { S.botulibrachium, } \\
\text { S.divrsibranchium, } \\
\text { S.subnigrum, } \\
\text { S.trravassosi, } \\
\text { S.paraguayense, } \\
\text { S.guianense, } \\
\text { S.nigrimanum, } \\
\text { S.scutistriatum } \\
\end{array}$ \\
\hline & Total: 27 espécies & & Total: 24 espécies & \\
\hline
\end{tabular}


Dentre as espécies evidenciadas, são hematófagas: S.pertinax, S.nigrimanum, S.rubritorax, S.inaequali, S.guianense, S.oyapockense, S.perflavum, S.distinctum, S.subnigrum, S.dinellii, S.paraguayense e S.incrostatum (BERTAZO et al., 2013; COSCARÓN et al., 2011; EATON et al., 1998; ARRUDA, 2014; PEREIRA, 2011).

Entre os simulídeos de importância médica da região Sudeste, encontra-se o S.pertinax, sendo descrito como uma espécie de ampla distribuição no Brasil e na região. É bem adaptado a ambientes modificados pelo ser humano, conseguindo tolerar altos níveis de antropifização, preferindo, em muitos casos, ambientes bem oxigenados e com uma quantidade grande de nutrientes dispersos na correnteza. É uma espécie confirmada em obras literárias como vetor eficaz de parasitas, característica atrelada ao fato de se adaptar bem a ambientes antropofizados. Dentre os parasitas transmitidos por sua picada, está o Onchorceca volvulus, causador da Oncorcecose e a Mansonella.spp, causadora da Mansolenose. Essa espécie tem, como preferência, microambientes dotados de folhagem e, em certos casos, compostos por plásticos descartados indevidamente, fixando-se em folhagem que se estão localizadas, em regiões mais fracas da correnteza, onde a vasão de água é suave o que facilita a sua adesão no substrato e alimentação. Eles são encontrados abundantemente em diferentes níveis de rios e riachos, grandes ou pequenos (DELLOME FILHO, 1991; PETRY et al., 2004; LOZOVEI et al., 2004; RIBEIRO, 2018; NOVICKI, 2017; COPPO et al., 2010).

Uma das espécies bem adaptadas a ambientes colonizados por seres humanos é o $S$. inaequale, uma espécie com preferência por substrato vegetal como: galhos e folhas, além de lixo não biodegradável humano, por conta da sua preferência por locais com vasão mais fraca. Contudo, raramente são encontrados em rochas e, quando encontrados, ocorrem em menor abundância, por se tratar de um substrato mais relacionado a correntezas mais potentes que dificultam sua adesão no substrato e alimentação. Esses organismos preferem corredeiras suaves com grande abundância de nutrientes e não necessitam de grande quantidade de oxigênio. Na maioria dos casos, são considerados como pragas em rios onde há criações de animais como, por exemplo, peixes e crustáceos, por conta da grande quantidade de nutrientes provenientes da alimentação e fezes desses animais. Essa espécie de simulídeo não foi apresentada como um vetor até o presente momento. Entretanto, mesmo não sendo um inseto vetorial, o mesmo apresenta capacidade de gerar enfermidades em humanos e animais, já que sua picada gera diferentes problemas alérgicos e debilitantes (DELLOME FILHO, 1991; PETRY et al., 2004; LOZOVEI et al., 2004; PEREIRA, 2011; NOVICKI, 2017; COPPO et al., 2010).

Outra espécie colonizadora de ambientes ricos em folhagem é o S.incrustatum que, apesar de ser adaptado à hematofagia em humanos, não tolera níveis elevados de perturbação ambiental, como os S.pertinax e o S.inaequale, sendo pouco abundante em ambientes muito alterados pelo ser humano. Esses organismos vivem principalmente em córregos, preferindo aqueles com correntezas mais lentas e bastante folhagem, colonizando folhas e galhos em decomposição lançados no fluxo de água, além de serem encontrados também em substratos artificiais, como plásticos descartados. São considerados, na região 
Centro-oeste, Sul e Sudeste, uma praga vetorial pelo fato de ser um dos vetores de filárias nessas regiões (DELLOME FILHO, 1998; RIBEIRO, 2018; LOZOVEI et al., 2004; NOVICKI, 2017; COPPO et al., 2010; PETRY et al., 2004; PEPINELLI et al., 2005).

As espécies de simulídeos S.perflavum, S.distinctum e S.subnigrum são exemplares com preferência por condições muito similares em seu estado larval. Foram encontrados em locais de corredeiras leves com substrato de folhagem e galhos. Contudo, há evidências em substratos artificiais, como plástico e tecido descartados em meio à correnteza, apresentando preferência por águas bem oxigenadas e com pouca poluição ou interação humana no ambiente, por se tratarem de animais filtradores sensíveis a mudanças bruscas. Essas espécies não apresentam nenhuma afinidade com algum patógeno evidente até o presente momento, apesar de serem espécies hematófagas (PETRY et al., 2004; PEPINELLI, 2003; LOZOVEI et al., 2004; COPPO et al., 2010; DELLOME FILHO, 1991; PEREIRA, 2011).

Tratando-se de vetores de filárias, o S.oyapockense é conhecido como um dos principais vetores de filárias em regiões de contaminação dentre elas Onchorceca volvulus e Mansonella. Esse simulídeo ocorre preferencialmente em rios volumosos com correntezas fortes, porém se adapta a rios com pouca vazão, preferindo como substrato para se fixar as folhas e galhos, mas havendo ocorrência de sua fixação em plantas aquáticas próximas às margens de corpos de água (BERTAZO et al., 2013; PEREIRA, 2001).

Algumas espécies apresentam predileção por ambientes como rochas localizadas em locais com bastante vazão de água. No caso do S.dinelli, é preferível a fixação em ambientes contendo musgo, raízes e folhas com correntezas mais intensas e com água limpa e bem oxigenada, tais preferências estão relacionadas diretamente com o tamanho da larva mais avantajado precisando de um ambiente com bastante nutrientes, oxigênio e vazão de água para sua alimentação. Contudo, esses insetos podem ser também encontrados em raízes e folhas de plantas próximas as margens. O S.dinelli, apesar de ser capaz de realizar o repasto sanguíneo, não é uma espécie evidenciada como vetor, mesmo esse causando problemas por seu comportamento hematófago (PEPINELLI et al., 2005; COPPO et al., 2010).

Alojando-se em meio às rochas, musgos e raízes, podemos encontrar exemplares de $S$. rubritorax, outra espécie de ampla distribuição por certas áreas da região Sudeste do país como, por exemplo, em reservas do estado do Rio de Janeiro. É uma espécie sensível a mudanças bruscas no ambiente, prendendose a rochas e musgos principalmente. Além disso, são encontrados em correntezas bem oxigenadas e de ampla vazão, preferem locais com água limpa ou com níveis relativamente baixos de poluição, não se adaptando bem em locais com muitos nutrientes. É uma espécie que, apesar de ser hematófaga, não apresenta atividade vetorial, apenas detém de uma eficiência em gerar lesões e problemas alérgicos em animais e humanos (CASTRO, 2014; COPPO et al., 2010; NOVICKI, 2017).

Lugares ricos em raízes e rochas também são habitat de S.nigrimanum, um simulídeo com preferência atrelada diretamente à vazão de água, tendo preferência majoritária por regiões de corredeiras mais agressivas e, em certos casos, encontra-se em habitat formado por lixo humano não biodegradável represado, fixando-se muito raramente em folhagens no topo da correnteza. Eles são encontrados principalmente em rios de médio ou grande porte, habitando muito raramente córregos ou riachos lentos, 
se tratando principalmente por conta do seu tamanho avantajado e necessidade constante de nutrientes e oxigênio. É capaz de se adaptar bem em locais com população humana, sendo encontrados em cidades próximas a rios. Não são vetores evidentes de parasitas ou qualquer patógeno conhecido, porém, o contato constante com sua saliva, devido às picadas agressivas, pode ser causador de doenças imunológicas, dentre elas destaca-se o Fogo Selvagem (RIBEIRO et al., 2010; BEGEMANN, 1980; EATON et al., 1998; MACQUART, 1838; FIGUEIRÓ et al., 2012; LESTÓN et al., 2014).

Juntamente com o S.nigrimanum, o S.guianense é uma espécie com preferência por rios bem oxigenados e com corredeiras fortes, geralmente colonizando raízes de plantas ou rochas na região mais baixa da correnteza. Por conta dessas características, o S.guianense raramente é encontrado em rios e riachos de pouca vazão, prefere águas mais limpas, mas podem se adaptar a locais com interferência humana. Essa espécie já foi evidenciada como um dos principais vetores de filárias e parasitas sanguíneos provenientes da sua picada (VILLAMIZAR et al., 2011; CHAGAS, 2011; LESTÓN et al., 2014).

Tabela 2: Quantidade de artigos relacionados a predileção de substratos de cada espécie de simulideos hematófagos.

\begin{tabular}{|c|c|c|c|c|}
\hline Espécie & $\begin{array}{l}\text { Substrato } \\
\text { rochoso }\end{array}$ & $\begin{array}{l}\text { Substrato de } \\
\text { folhagem }\end{array}$ & $\begin{array}{l}\text { Substrato de } \\
\text { plantas } \\
\text { aquáticas }\end{array}$ & Referencias \\
\hline S,pertinax & 0 & 5 & 0 & $\begin{array}{l}\text { LOZOVEI et al. (2004), NOVICKI (2017), COPPO et al. } \\
\text { (2010), DELLOME FILHO (1991), PETRY (2004) }\end{array}$ \\
\hline S.distinctum & 0 & 2 & 0 & PETRY (2004), LOZOVEI et al. (2004) \\
\hline S.inaequali & 0 & 6 & 0 & $\begin{array}{l}\text { PEREIRA (2011), LOZOVEI et al. (2004), NOVICKI (2017), } \\
\text { COPPO et al. (2010), DELLOME FILHO (1991), PETRY } \\
\text { (2004) }\end{array}$ \\
\hline S.incrustatum & 0 & 6 & 0 & $\begin{array}{l}\text { LOZOVEI et al. (2004), NOVICKI (2017), PEPINELLI et al. } \\
\text { (2005), COPPO et al. (2010), DELLOME FILHO (1991), } \\
\text { PETRY (2004) }\end{array}$ \\
\hline S.rubrithorax, & 2 & 0 & 0 & COPPO et al. (2010), NOVICKI (2017) \\
\hline S.guianense & 2 & 0 & 0 & VILLAMIZAR et al. (2011), LESTÓN (2014) \\
\hline S.nigrimanum & 2 & 0 & 0 & FIGUEIRÓ et al. (2012), LESTÓN et al. (2014) \\
\hline S.oyapockense & 0 & 1 & 0 & PEREIRA (2001) BERTAZO et al. (2013) \\
\hline S.perflavum & 0 & 2 & 0 & PEREIRA (2011), LOZOVEI et al. (2004) \\
\hline S.subnigrum & 0 & 4 & 0 & $\begin{array}{l}\text { PEPINELLI (2003); LOZOVEI et al. (2004); COPPO et al. } \\
\text { (2010); PEREIRA, } 2011\end{array}$ \\
\hline S.dinnelii & 0 & 0 & 2 & PEPINELLI et al. (2005), COPPO et al. (2010) \\
\hline
\end{tabular}

Apesar das pesquisas e observações literárias, não se tem registros conclusivos da preferência por substrato e da importância médica e veterinária atrelada à espécie S.paraguaiyense, sendo essa espécie hematófaga não muito conhecida e estudada (COSCARÓN et al., 2011).

O comportamento de espécies hematófagas pode auxiliar no desenvolvimento de estratégias profiláticas contra imaturos da família Simuliidae, como a retirada do substrato de preferência, aplicação de produtos químicos e biológicos ou raspagem dos substratos, sendo em espécies observadas como preferivelmente de substratos de folhagem tendo como principal controle a retirda dematerial vegetal disperso na corrente, juntamente com os exemplares majoritariamente encontrados em regiões roxosas e fixados em plantas tem como principal método a raspagem destes locais. Juntamente com as medidas físicas, podem ser feitas medidas educacionais e de conservação ambientam, para melhor entendimento da população sobre os simulídeos e por consequência a diminuição de despejo de materiais nos rios. Dessa forma, evitar-se-ia que essas espécies disseminassem doenças em populações que vivem perto de rios e 
riachos, além de contribuir para conservação de espécies que não são prejudiciais e desempenham um papel ambiental significativo no local (SIMON, 2012).

\section{CONCLUSÕES}

A partir dos dados e resultados obtidos e pelos registros bibliográficos encontrados, pode-se concluir que foram encontradas 51 espécies de simulídeos já descritas para região Sudeste, em que 12 delas são consideradas hematófagas ou causam alguma comorbidade a seres humanos e animais. Dentre as espécies hematófagas encontradas estão: S pertinax, S.inaequali, S.perflavum, S.distaltum e S.incrostatum que tem como substrato de preferência folhagens e materiais em decomposição em meio à correnteza. Assim, sugerese que, para tais espécies, a principal profilaxia a ser adotada é o controle e a retirada de material em meio à correnteza.

Dentre as espécies localizadas preferencialmente em substratos como raízes, rochas e musgo têm: S.nigrimanum, S.rubritorax, S.guianense, e S.dinellii. Tratando-se de espécies com preferência por substratos mais estáticos, como rochas, a retirada do microambiente se torna algo inviável ou minimamente complicado, porém, podem-se utilizar técnicas como raspagem das rochas periodicamente para retirada de estágios iniciais, evitando, assim, o desenvolvimento do inseto.

\section{REFERÊNCIAS}

ALVES, M. V.. Atividade Larvicida de Bacillus spp. da Amazônia brasileira portadores dos genes Cry e BSglu ( $\beta$ Glucanase), no controle de Aedes Aegypti Linnaeus, 1762. 2019.

AMARAL-CALVÃO, A. M. R.; MAIA-HERZOG, M.. Adolpho Lutz's collection of black flies (Diptera- Simuliidae), its history and importance. História, Ciências, Saúde Manguinhos, Rio de Janeiro, v.10, n.1, p.259-271, 2003.

ANDRADE, H. T. A.; PY-DANIEL, V.; MEDEIROS, J.; PESSOA, F. . Considerações sobre simulídeos (Diptera-Simuliidae) e filarioses (Oncocercose e Mansonelose). Revista Cultural e Científica Carpe Diem, Natal, v.2-3, n.2-3, p.91-108, 2003.

ARRUDA, E. J.. Suscetibilidade de Larvas de Simulídeos ao Larvicida Temephos em Caarapó, MS. BioAssay, v.9, 2014.

BEGEMANN, G. J.. Laboratory studies on the biology of Simulium nigritarse Coquillett and Simulium adersi Pomeroy (Diptera: Simuliidae). Onderstepoort Journal of Veterinary Research, Bloemfontein, v.47, n.4, p.203211, 1980.

BERTAZO, K.; HAMADA, N.; SALLES, F. F.. Fauna of Simuliidae (Diptera) from the state of Espírito Santo, Brazil: distribution, new records and list of species. Revista Brasileira de Entomologia, v.57, n.1, p.91-99, 2013.

BERTAZO, K.; SANTOS, C. B.; PINTO, I. S.; FERREIRA, A. L.; FALQUETO, A.; PEPINELLI, M.. Distribuição de espécies de borrachudos (Diptera: simuliidae) do Espírito Santo, Brasil. Biota Neotropica, v.10, n.3, p.129-132, 2010.

BUFFOLO, I. R. A.; SOUZA, T. M. M.; SANTOS, S. S.; RODRIGUES, T.; BERBERT, L. C.; DOCILE, T. N.; FIGUEIRÓ, R..
Desvendando os padrões de preferência de habitat de larvas de simuliidae (diptera) neotropicais e suas implicações para o controle do vetor. Acta Biomédica Brasiliensia, v.7, n.1, p.109-123, 2016.

CASTRO, B. S. F.. Diversidade Genética de Populações de Simulium Rubrithorax Lutz (diptera: simuliidae) utilizando o Gene Mitocondrial Citocromo Oxidase I (coi). In: CONGRESSO DE INICIAÇÃO CIENTÍFICA DO INPA - CONIC, 3. Anais. 2014.

CHAGAS, A. C.. Estudo da glândula salivar do principal vetor da oncocercose no Brasil, Thyrsopelmaguianense (Diptera: Simuliidae): Aspectosmorfológicos, bioquímicos e moleculares. Diss. 2011.

COPPO, T. L.; LOPES, J.. Diversidade de Simuliidae (Diptera: Nematocera) de três cursos d'água no parque ecológico da Klabin SA-Telêmaco Borba, Estado do Paraná. Semina: Ciências Biológicas e da Saúde, v.31, n.1, p.03-14, 2010.

COSCARÓN, S.. Insecta, Díptera, Simuliidae. In: RINGUELET, R. A.. Fauna de agua dulce de la Republica Argentina. v.38. Buenos Aires: FECIC, 1981.

COSCARÓN, S.; MOREIRA, G. R. P; PY-DANIEL, V.; SATO, G.; NASCIMENTO, É. S.; MAIA-HERZOG, M.. The blackflies (Diptera: simuliidae) from Santa Catarina, Brazil. Zoologia, Curitiba, v.28, n.1, p.31-36, 2011. Dol: http://dx.doi.org/10.1590/s1984-46702011000100005

CROSSKEY, R. W.. The Natural History of Blackflies. Londres: Wiley-Blackwell, 1990.

DELLOME FILHO, J.. Simuliofauna do rio Marumbi (Morretes, 
PR, Brasil). I. Coleta e criação; dados meteorológicos e físicoquímicos do criadouro; adultos (Diptera, Simuliidae). Acta Biológica Paranaense, v.20, 1991.

EATON, D. P.; DIAZ, L.; HANS FILHO, G.; SANTOS, V.; AOKI, V.; FRIEDMAN, H.; RIVITTI, E. A.; SAMPAIO, S. A. P.; GOTTLIEB, M. S.; GIUDICE, G. J.; LÓPEZ-LUNA, A.; CUPP, E. W.. Comparison of Blackfly Species (Diptera: Simuliidae) on an Amerindian reservation with a high prevalence of Fogo Selvagem to neighboring disease-free sites in the state of Mato Grosso do Sul, Brazil. Journal of Medical Entomology, Oxford, v.35, n.2, p.120-131, 1998.

FARIAS, P. R. S.. Manual de entomologia geral. Belém: UFRA, 2013.

FIGUEIRÓ, R.; GIL-AZEVEDO, L. H.; MAIA-HERZOG, M.; MONTEIRO, R. F.. Diversity and micro distribution of blackfly (Diptera: simuliidae) assemblages in the tropical savanna streams of the Brazilian cerrado. Memórias do Instituto Oswaldo Cruz, v.107, n.3, p.362-369, 2012.

FONTES, G.; BRAU, R. F.; FRAIHA NETO, H.; VIEIRA, J. B. F.; PADILHA, S. S.; ROCHA, R. C.; ROCHA, E. M. M.. Filariose linfática em Belém, Estado do Pará, Norte do Brasil e a perspectiva de eliminação. Revista da Sociedade Brasileira de Medicina Tropical, v.38, n.2, p.131-136, 2005. DOI: https://doi.org/10.1590/S0037-86822005000200001

GIL-AZEVEDO, L. H., MAIA-HERZOG, M.. Espécies de Simuliidae (Diptera) registradas no estado do Rio de Janeiro, Brasil. Arquivos do Museu Nacional, Rio de Janeiro, v.67, n.3-4, p.349-354, 2009.

GIL-AZEVEDO, L. H.; MOLINA, O. S.; SANTOS, D. S.. Simuliidae do Estado do Rio de Janeiro. 2014.

GIL-AZEVEDO, L.; H.; SANTOS-MALLET, J. R.; MAIA-HERZOG, M.. Caracteres diagnósticos de Simulium (Chirostilbia) pertina x Kollar (Diptera: Simuliidae). Neotropical Entomology, Londrina, v.33, n.4, 2004.

GIL-AZEVEDO, L. H.; FERREIRA JUNIOR, N.; MAIA-HERZOG, M.. Chave de identificação de pupas de Simuliidae (Diptera) do Sudeste do Brasil. Revista Brasileira de Zoologia, v.22, n.3, p.742-752, 2005.

GINARTE, C. A.; ANDRADE, C. F. S.; GAONA, J. C.. Larvas de simulídeos (Diptera, Simuliidae) do Centro Oeste, Sudeste e Sul do Brasil, parasitadas por microsporídeos (Protozoa) e mermitídeos (Nematoda). Iheringia, Série Zoologia, v.93, n.3, p.325-334, 2003.

LOZOVEI, A. L.; PETRY, F.; SANTOS NETO, L. G.; FERRAZ, M. E.. Levantamento das espécies de Simulium (Diptera, Simuliidae), Riacho dos Padres, município de Almirante Tamandaré, Paraná, Brasil. Revista Brasileira de Entomologia, v.48, n.1, p.91-94, 2004. DOI: https://doi.org/10.1590/S0085-56262004000100015

LESTÓN, V.; DÍAZ, J.; VÁZQUEZ, F. Q.; COBO, F.. Distribución y selección de sustrato de los Simuliidae (Diptera) eneltramomediodelríoSerpis (sureste de España). 2014.

MACQUART, J.. Diptèresexotiques nouveaux ou peuconnus. Roret, 1838.
NOVICKI, D.. Diversidade de simulídeos (diptera: simuliidae) em riachos da bacia do Rio Comandaí, Alto Rio Uruguai. 2017.

PETRY, F.; LOZOVEI, A. L.; FERRAZ, M. E.; SANTOS NETO, L. G.. Controle integrado de espécies de Simulium (Diptera, Simuliidae) por Bacillusthuringiensis e manejos mecânicos no riacho e nos vertedouros de tanques de piscicultura, Almirante Tamandaré, Paraná, Brasil. Revista Brasileira de Entomologia, v.48, n.1, p.127-132, 2004.

PETRY, F.. Aspectos biológicos de fertilidade e ciclo evolutivo de espécies de Simulium (Diptera, Simuliidae) e susceptibilidade de suas larvas em bioensaios laboratoriais com formulados de Bacillusthuringiensisisraelensis em aparato elaborado. Dissertação (Mestrado em Ciências Biológicas) - Universidade Federal do Paraná, Curitiba, 2005.

PETRY, F.; LEUCHLOZOVEI, A.; CHAHAD-EHLERS, S.. Eggs fertility and biological aspects of the life cycle in natural populations of Simulium (Diptera, Simuliidae). Brazilian Archives of Biology and Technology, v.49, n.5, p.799-805, 2006.

PEPINELLI, M.. Diversidade de Similiidae (Diptera, Nematocera) em córregos do estado de São Paulo, Brasil. 2003.

PEPINELLI, M.; HAMADA, N.; TRIVINHO-STRIXINO, S.. Simulium (Thyrsopelma) duodenicornium, a new blackfly species (Diptera: simuliidae) from the Southeast Region of Brazil. Zootaxa, v.1040, n.1, p.17-29, 2005.

PEREIRA, E. S.. Obtenção de novas estirpes de bacillusthuringiensis Berliner patogênicas a larvas de Simuliidae e caracterização molecular de populações de simulium (chirostilbia) pertinaxKollar (Díptera: Simuliidae) no Brasil. 2011.

PEREIRA, E. S.. Citotaxonomia de Simulium Oyapockense SL (diptera: Simuliidae) da Área de São Gabriel da Cacheira, Am. In: JORNADA DE INICIAÇÃO CIENTÍFICA DO PIBIC/INPA, 10. Anais. 2001.

RIBEIRO, J. M.; VALENZUELA, J. G.; PHAM, M. V.; KLEEMAN, L.; BARBIAN, K. D.; FAVREAU, A. J.; EATON, D. P.; AOKI, V.; HANS FILHO, G.; RIVITTI, E. A.; DIAZ, A L.. An insight into the sea lotranscriptome of Simuliumnigrimanum, a blackfly associated with Fogo Selvagem in South America. The American Journal of Tropical Medicine and Hygiene, Baltimore, v.82, n.6, p.1060-1075, 2010.

RIBEIRO, L. M. L.. Inventário bibliográfico dos estudos envolvendo Diptera:Simuliidae em áreas impactadas por empreendimentos de grande porte. 2018.

SHELLEY, A. J.; SHELLEY, A.. Futher evidence for the transmission of Mansonella ozzardi by Simulium amazonicum. Annals of Tropical Medicine \& Parasitology, Brasília, v.70, n.2, p.213-217, 1976.

SIMON, Y. G.. Controle de simulídeos: uma visão de gerenciamento. 2012.

TAUIL, P. L.. Aspectos críticos do controle do dengue no Brasil. Cadernos de Saúde Pública, v.18, n.3, p.867-871, 2002. 
VILLAMIZAR, N.; CORTEZ, J.; ALARCON, O. N.; ESCALONA, M.; BOTTO, C.; GRILLET, M.. Primera descripción del hábitat acuático de Simulium guianense s.I. (Diptera: Simuliidae) enel área endémica de oncocercosis, alsur de Venezuela. Bol. Mal. SaludAmb, Maracay, v.51, n.1, p.97-101, 2011.
VIVIANI, A. B. P.; ARAÚJO-COUTINHO, C. J. P. C.; MORAES, R. B.; GIL, H. B.; LEUNG, R.; CAMARGO, A. F. M.. Distribuição e abundância de larvas de Simulium spp. em córregos do estado de São Paulo nos diferentes níveis de qualidade da água. Neotropical Biology and Conservation, v.7, n.1, p.4856,2012

A CBPC - Companhia Brasileira de Produção Científica (CNPJ: 11.221.422/0001-03) detém os direitos materiais desta publicação. Os direitos referem-se à publicação do trabalho em qualquer parte do mundo, incluindo os direitos às renovações, expansões e disseminações da contribuição, bem como outros direitos subsidiários. Todos os trabalhos publicados eletronicamente poderão posteriormente ser publicados em coletâneas impressas sob coordenação da Sustenere Publishing, da Companhia Brasileira de Produção Científica e seus parceiros autorizados. Os (as) autores (as) preservam os direitos autorais, mas não têm permissão para a publicação da contribuição em outro meio, impresso ou digital, em português ou em tradução. 